\title{
Coronary Bilateral Ostial Enlargement Using the Saphenous Vein in a Patient with Syphilitic Aortitis
}

\author{
Ulisses A. Croti, Francisco Gregori Jr, Miguel B. Marcial, Luís A. Dallan, Thelma Elisa F. Gregori, \\ Divina S. O liveira
}

São Paulo, SP - Brazil

\begin{abstract}
A patient with tertiary syphilis presenting with bilateral coronary ostial lesions - and aortic regurgitation underwent surgical reconstruction of the coronary ostia by the anterior approach with autogenous saphenous vein grafting and substitution of the aortic valve with a bovine bioprosthesis. The procedure was easily performed and had good outcomes both early and late. The rarity of the association of a lesion in both coronary ostia with aortic regurgitation in syphilis and the surgical technique employed are discussed.
\end{abstract}

Syphilis has been succesfully controlled in recent years; involvement of the heart and the aorta have become relatively rare events. The incidence and degree of seriousness of syphilitic aortitis is greater in the initial portion of the ascending aorta involving the coronary ostia and the valvulae of the aortic valve. Heggtveit ${ }^{1}$, in a clinicopathological review of syphilitic aortitis, noted uni or bilateral coronary ostial stenosis with aortic regurgitation in $14 \%$ of patients.

Several surgical tactics for the correction of coronary ostial stenosis have been reported: endarterectomy ${ }^{2-5}$, aorto-coronary bridging with either arterial ${ }^{6,7}$ or venous ${ }^{4}$ grafts or both, and ostial reconstruction via the anterior ${ }^{3,8}$ or posterior ${ }^{8,9}$ approaches.

We have performed surgical treatment of a patient presenting with bilateral coronary lesions and aortic regurgitation by ostial amplification via the anterior approach. Along with the aortic valve substitution, we used grafting with autogenous saphenous vein to reconstruct both coronary ostia.

\section{Case Report}

A forty-eight-year old male Caucasian patient related a history of two months of intense nonirradiating precordial pain unrelated to effort, dyspnea, throbbing and decreased visual accuity. In his past medical history, he reported several episodes of veneral disease but denied the existence of familial heart disease.

Instituto do Coração do Hospital das Clínicas - FMUSP

Mailing address: Ulisses A. Corti - Incor - Av. Dr. Enéas C. Aguiar, $44-2^{\circ}-\mathrm{S} / 10$

- 05403-900 - S. Paulo, SP - Brazil

Received on $6 / 24 / 99$

Accepted on $9 / 15 / 99$
Upon examination, the patient was in good physical condition, eupneic, with arterial blood pressure of 16/40mm$\mathrm{Hg}$ in the right upper limb and 70/40 $\mathrm{mmHg}$ in the left upper limb; his left radial and arm pulses were of lower amplitude relative to the right, which showed strong pounding feature. The first heart sound was normal, the second was of decreased intensity, with a protomesodiastolic regurgitative murmur $++/++++$ in aortic and accessory aortic areas.

The thoracic radiograph revealed aortic ectasia and a normal cardiac area. The electrocardiogram showed a sinusal rhythm, QRS axis AT $+30^{\circ}$, T wave negative at $4 \mathrm{~V}$, flattened at V5 and V6, Dl and the VL with left ventricular hypertrophy. Dopplerechocardiography showed diffuse hypokinesia of the left ventricle and moderate aortic regurgitation with ectasia of the ascending aorta. A cinecoronariographic study showed $70 \%$ obstruction of the left coronary ostium, $60 \%$ of the right coronary ostium, serious aortic regurgitation and a critical lesion in the left subclavian artery that was treated by percutaneous transluminal coronary angioplasty at the time of diagnosis. Results of routine laboratory tests were normal with the exception of the Venereal Disease Research Laboratory test (VDRL), reactive at 1:64 dilution and positive fluorescent treponemal antibody-absorption test (FTA-ABS).

The surgical approach was performed by medial sternotomy, aortic and right atrial cannulation, and extracorporeal circulation under moderate hypothermia at $30^{\circ} \mathrm{C}$. Myocardial protection was afforded by St. Thomas crystalloid solution.

The aorta was transversally incised in its anterior wall, a pronounced inflammatory condition being observed. Following inspection of the coronary ostia, we decided on their amplification using segments of the autogenous saphenous vein, rather than aorto-coronary grafting. The left coronary ostium was treated by extending the incision through the left lateral wall towards the interior of the coronary trunk and to the bifurcation of the interventricular anterior and circumflex branches. To facilitate exposure, the pulmonary artery was pushed aside laterally. A longitudinally opened graft of the saphenous artery was inserted with a continuous suture (7-0 propylene), beginning at the bifurcaton of the left coronary trunk, passing through the ostium in the direction of the anterior aspect of the aortectomy, and 
propitiating adequate amplification of the left coronary ostium, which increased from one to $5 \mathrm{~mm}$.

Inspection of the right coronary ostium confirmed its stenosis ( $1.5 \mathrm{~mm}$ diameter). A T-shape incision was made starting at the lower border of the aortotomy, through the ostium, reaching near to the sinusal branch. From this point on, a graft of the autogenous saphenous vein was sutured until the transversal incision of the aorta was reached, permitting ostial amplification to approximately $4.5 \mathrm{~mm}$.

The aortic valve did not allow for repair surgery and was replaced with a bovine pericardial prosthesis fixed in glutaraldehyde and preserved in formaldehyde $23 \mathrm{~mm}$ (Braile-Biomédica-São José do Rio Preto, SP - Brazil). The perfusion time was $85 \mathrm{~min}$; myocardial anoxia lasted $73 \mathrm{~min}$.

During the first hours of the postoperative period, the patient's electrocardiogram indicated a subepicardial lesion in the antero-septal wall, without hemodynamic alterations; cardiac catheterization was performed. Good functioning of the biological prosthesis and a significant amplification of the coronary ostia (figs. 1 and 2) with adequate flow to all coronary arteries was observed; the cause of the electrocardiographic chnges was not identified.

Pathological analysis of fragments removed from the aorta showed atherosclerosis and intense lymphoblastic
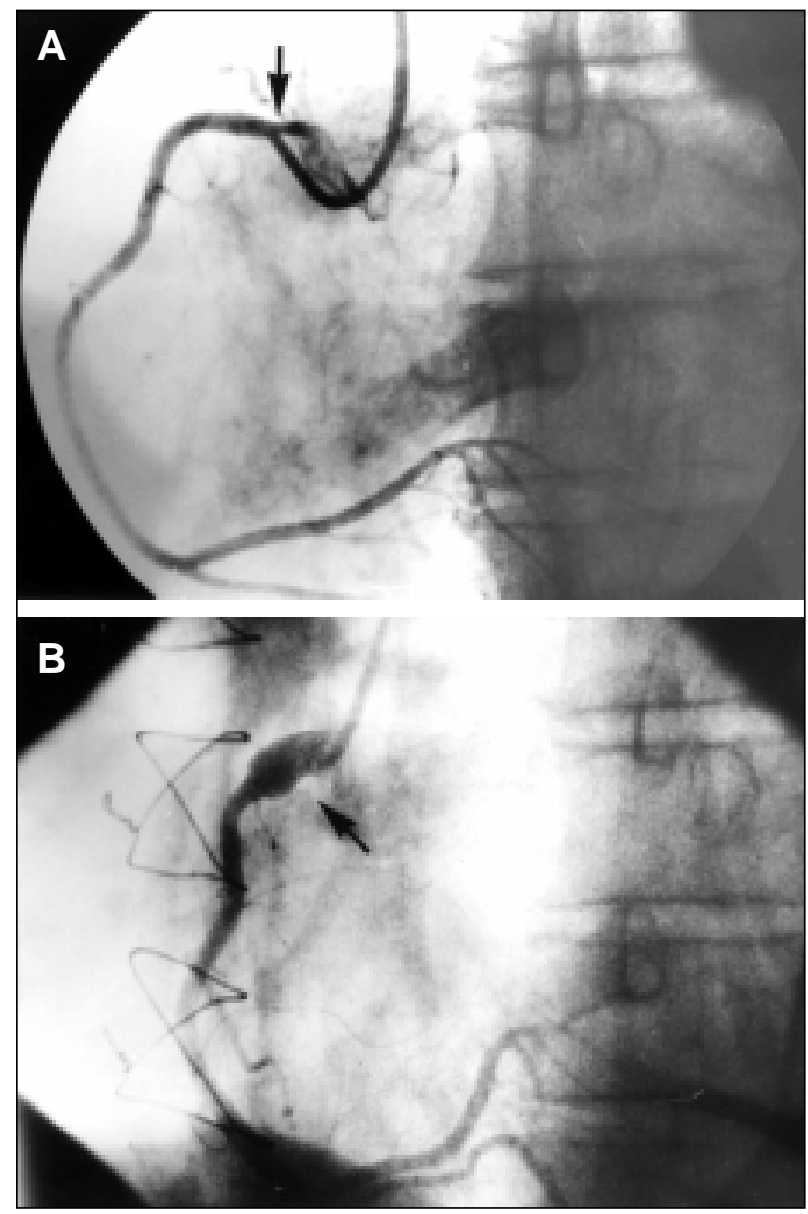

Fig. 1 - Right coronary - preoperative cinecoronariography: significant stenosis of the coronary ostium is observed; postoperative cinecoronario-graphy demonstrates adequate ostial amplification.
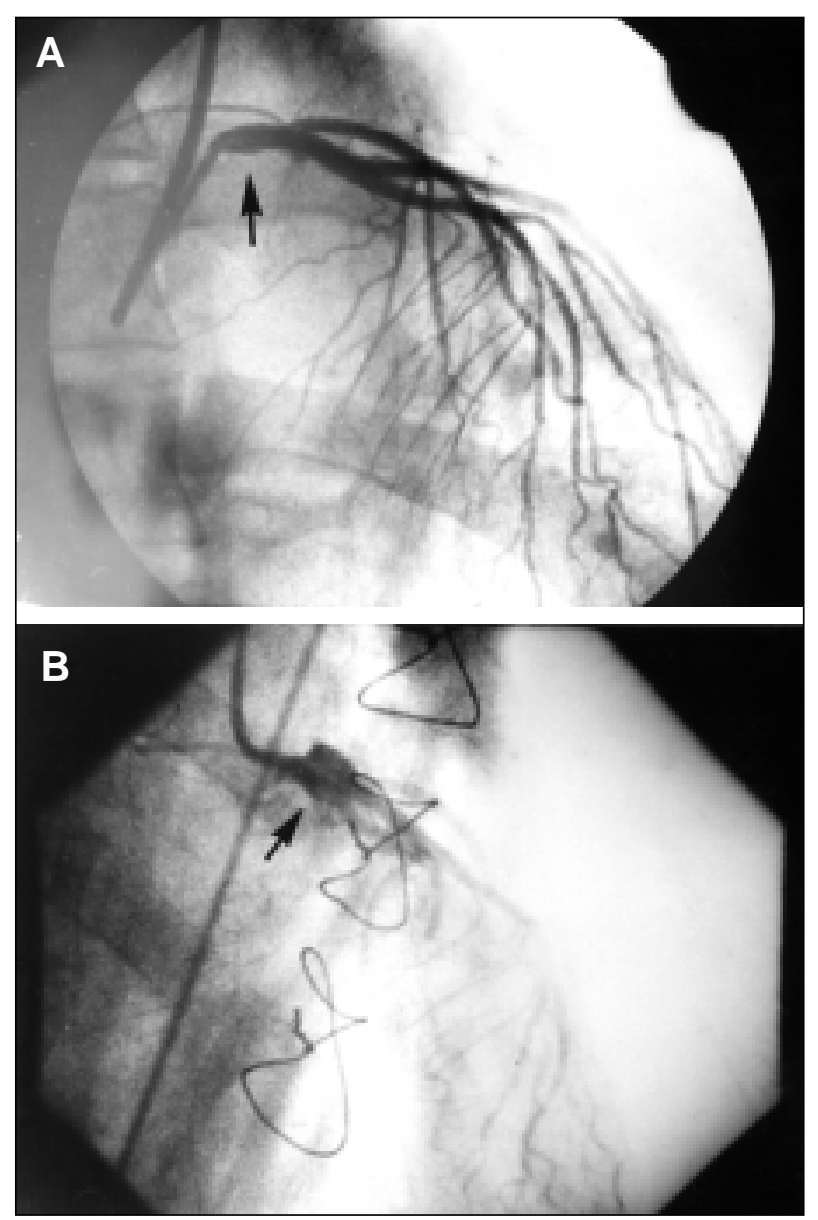

Fig. 2 - Left coronary - preoperative cinecoronariography: significant stenosis of the coronary ostium is observed; postoperative cinecoronariography demonstrates adequate ostial amplification.

infiltration in the medial and adventitial layers of the vessel (fig. 3) confirming a luetic cause.

The patient had no further intercurrent events, receiving his hospital discharge on the eighth day following the operation, He was followed on an outpatient basis with antibiotic therapy adequate for the treatment of tertiary syphilis. After a three-year follow-up period, he does not have angina, and myocardial scintigraphy does not indicate signs of ischemia.

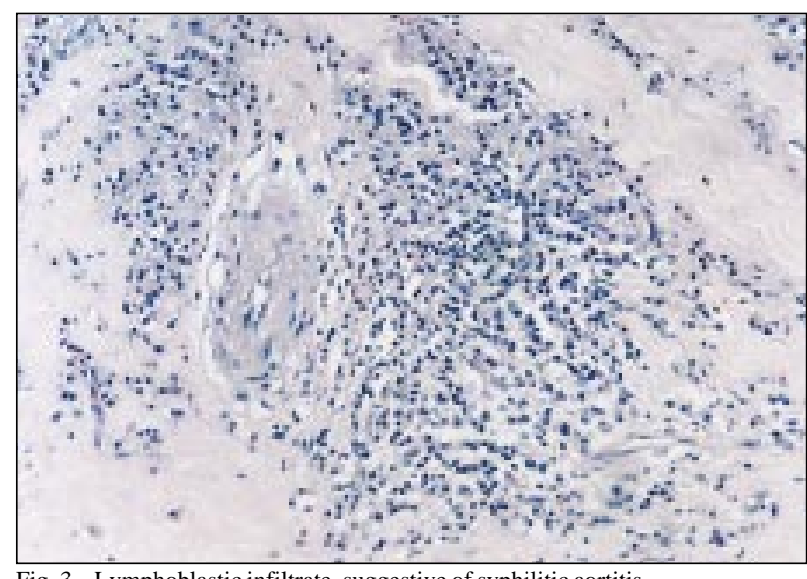

Fig. 3 - Lymphoblastic infiltrate, suggestive of syphilitic aortitis. 


\section{Discussion}

Syphilis affects the cardiovascular system in various ways.Aortitis is the most severe and frequent outcome, which leads to the formation of aneurysms, aortic regurgitation and coronary ostial stenosis. Heggtveit ${ }^{1}$ in a study of 100 patients with aortic syphilis found 26 cases of ostial stenosis, 14 of which were associated with aortic regurgitation.

The first surgical disobstruction of coronary ostia due to syphilitic disease, was performed by endarterectomy in $1959^{2}$. Conolly et al ${ }^{5}$ in 1964 reported a further case of endarterectomy of the right coronary ostium associated with valve repair due to aortic regurgitation.

Ostial lesions conventionally have been treated with myocardial revascularization techniques ${ }^{4,6,7}$, including either the left or the right internal thoracic artery or both of these, or their combination with saphenous vein grafting. This surgical option can be inconvenient because of coronary trunk occlusion, competitive flow, the coronary steal phenomenon, retrograde perfusion over an extensive myocardial area and the requirement for future surgical interventions, especially in young patients.

Ostial reconstructive surgery was first reconsidered after 1983 when Hitchcock et al. ${ }^{9}$ obtained favorable results by approaching the coronary ostium and trunk, restoring physiological perfusion of the myocardium. The authors used the posterior approach to the aorta with an incision through its floor and ostial amplification with a segment of the autogenous saphenous vein. This technique was modified by others ${ }^{3}$ who aimed to control eventual bleeding in the suture area.
Sullivan and Murphy ${ }^{3}$ advocated repair surgery by the anterior approach with autogenic saphenous vein grafting rather than using the posterior approach, because it presents a more frontal vision and greater ease of execution. Dion et al ${ }^{8}$ reported on a series of patients who underwent ostial repair by the anterior and posterior approaches, using the saphenous vein and the autogenous pericardium as grafting materials. Bortolotti et al ${ }^{10}$ described 4 patients with ostial coronary lesions treated by surgical repair; one of the patients had bilateral ostial lesions of syphilitic origin: amplification was made with the autologous pericardium.

In the present case, the surgical approach by the anterior method using saphenous vein grafts for the reconstruction of both coronary ostia, a rarely used procedure in luetic aortitis, was employed. This technique appeared to be the most adequate form of re-establishing coronary flow in this patient, because it permited the amplification of stenosed ostia and avoided possible complications associated with classical myocardial revascularization.

We believe that our choice was adequate, yielding excellent early and late post- operative results and adding a further surgical alternative to the treatment of ostial lesions of syphilitic origin.

\section{Acknowlegment}

We thank Dr. Danton R. Loures for bibliographic assistance.

\section{References}

1. Heggtveit HA. Syphilitic Aortitis. A Clinicopathologic Autopsy Study of 100 Cases, 1950 to 1960. Circulation 1964; 29: 346-55.

2. Dubost $\mathrm{CH}$, Blondeau PH, Piwnica A, et al. Syphilitic coronary obstruction: correction under artificial heart-lung and profound hypothermia at $10^{\circ} \mathrm{C}$. Surgery 1960: 540-7.

3, Sullivan JA, Murphy DA. Surgical repair of stenotic ostial lesions of the left main coronary artery. J Thorac Cardiovasc Surg 1989; 98: 33-6.

4. Yamada T, Sakamoto T, Asano K. Surgical treatment of syphilitic coronary ostial stenosis with aortic regurgitation. J Cardiovasc Surg 1983; 24: 222-6.

5. Connolly JE, Eldrigde FL, Calvin JW, Stemmer EA. Proximal Coronary-Artery Obstruction - Its Etiology and Treatment by Transaortic Endarterectomy. N Engl J Med 1964; 271: 213-9.
6. Vijayanagar R, Bognolo D, Eckstein P, et al. Safety and efficacy of internal mammary artery grafts for left main coronary artery disease. J Cardiovasc Surg 1987; 28: $576-80$.

7. Ogino K, Tokuyasu Y, Motomiya T, Sugiura M, Endo M. Bilateral Coronary Ostial Stenosis Associated with Aortitis Syndrome. Chest 1991; 99: 1286-7.

8. Dion R, Verhelst R, Matta A, Rosseau M, Goenen M, Chalant C. Surgical angioplasty of the left main coronary artery. J Thorac Cardiovasc Surg 1990; 99: 241-50.

9. Hitchcock JF, Robles de Medina EOR, Jambroes G. Angioplasty of the left main coronary artery for isolated left main coronary artery disease. J Thorac Cardiovasc Surg 1983; 85: 880-4.

10. Bortollotti U, Milano A, Balbarini A, et al. Surgical angioplasty for isolated coronary ostial stenosis. Tex Heart Inst J 1997; 24: 366-71. 